\title{
Photodegradation of Rhodamine 6G dye by Cd, Sr doped ZnO Photocatalyst, Synthesized by Mechanochemical Method
}

\author{
S. Salvi ${ }^{1}$, P. Lokhande ${ }^{2}$ and H. Mujawar ${ }^{3}$ \\ ${ }^{1}$ Research Scholar, ${ }^{2}$ AssociateProfessor, ${ }^{3}$ Professor, Dr.Babasaheb Ambedkar Technological University, Lonere, India \\ \{snehasalvi19june@gmail.com\}
}

\begin{abstract}
In the present investigation, synthesis of $\mathrm{Cd}$, Sr doped $\mathrm{ZnO}$ semiconducting material was carried out by ecofriendly simple mechanochemical method. The grinding of Oxalic acid, Zinc acetate, Cadmium acetate and Strontium acetate in mortar and pestle at non-stoichiometric proportion allowed these reactant to react and to form $\mathrm{Cd}$, Sr doped $\mathrm{ZnO}$ Photocatalyst, after thermal treatment to intermediate metal oxalate. SEM reveals the rod shape of material and EDX confirmed the incorporation of $\mathrm{Cd}$ and $\mathrm{Sr}$ in the crystal lattice of $\mathrm{ZnO}$. The reduction of photocatalytic activity of $\mathrm{Cd}$, $\mathrm{Sr}$ doped $\mathrm{ZnO}$ semiconducting microsize material was observed for Rhodamine $6 \mathrm{G}$ dye in UV light with pure $\mathrm{ZnO}$.
\end{abstract}

Keywords: $\mathrm{Cd}$, Sr doped $\mathrm{ZnO}$, mechanochemical, photocatalyst, EDX

\section{Introduction}

Zinc oxide is a II-IV semiconductor and has attracted much attention as a photo catalyst with large band gap 3.4 $\mathrm{eV}$ and a large exciton binding energy of $60 \mathrm{meV}$ at room temperature. $\mathrm{ZnO}$ have many applications such as Photocatalysts, Optoelectronics, Antibacterial activities, Pharmaceutical application, Photodetectors, Laser diodes [5]. Several methods have been used to synthesized $\mathrm{ZnO}$ and doped $\mathrm{ZnO}$ such as co-precipitation, precipitation, sol-gel, hydrothermal, oxalate precursor method etc. As zinc oxide has wide band gap it shows absorption in UV light [3]. However, the photo catalytic efficiency in solar light become highly efficient and economical compared to UV light. In order to get absorption in visible light, it is doped with metal or non-metal or combination of both. The photo catalytic activity mainly depends on creation of electron hole pair, which is able to form free radicals so as to undergo secondary reactions. The products obtain during degradation reaction are mineralized, non toxic i.e. $\mathrm{CO} 2$ and $\mathrm{H} 2 \mathrm{O}$.

Currently there is large development of dye industries because of civilization and modernization. At one side we are looking towards our needs and comfort but, at another sidethere is huge water pollution due to industrial waste. The polluted water mainly contains dye and these are used primarily in the production of consumer products including textile, printing inks, papers, paints and plastic. Because of high stability against temperature, light, chemicals and microbial attack, some organic dyes are slip away from conventional waste water treatment like ultra violet, reverse osmosis, nano and ultrafiltration [2]. Therefore, in need to develop new effective and economical technique for degradation of organic dye. Use of photo catalyst plays key role in degradation process.

Recently, the codoping has received increasing attention in photocatalyst area. The codopant will simultaneously trapped the photo induced electrons from conduction band of the zinc oxide and hence reduces the recombination rate of electron hole.

In some cases, doping increases the band gap of zinc oxide with increasing concentration of dopant and this is because of Fermi level merges into the conduction band with increase of carrier concentration and because of that, low energy transitions are blocked [4].

B. Iyer, S. Nalbalwar and R. Pawade (Eds.)

ICCASP/ICMMD-2016. Advances in Intelligent Systems Research.

Vol. 137, Pp. 48-53.

(C) 2017. The authors - Published by Atlantis Press

This is an open access article under the CC BY-NC license (http://creativecommons.org/licens)es/by-nc/4.0/).

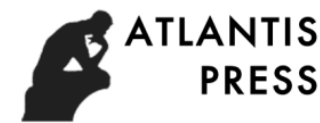




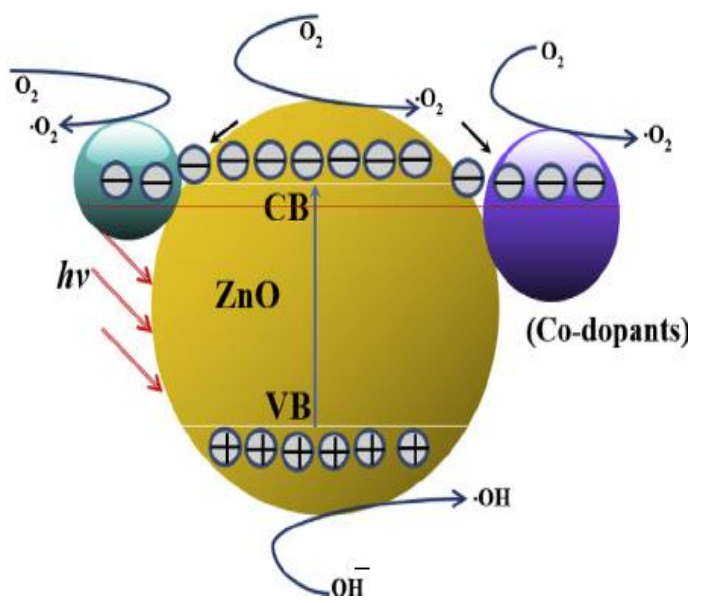

Fig. 1. Effect of Co-doping on photocatalytic degradation of dye

\section{Experimental work}

\subsection{Chemicals and Materials}

In the present study, Oxalic acid $(\mathrm{C} 2 \mathrm{H} 2 \mathrm{O} 4.2 \mathrm{H} 2 \mathrm{O})$, Zinc acetate $(\mathrm{Zn}(\mathrm{CH} 3 \mathrm{COO}) 2.2 \mathrm{H} 2 \mathrm{O})$, Cadmium acetate $(\mathrm{Cd}(\mathrm{CH} 3 \mathrm{COO}) 2.2 \mathrm{H} 2 \mathrm{O})$, Strontium acetate $(\mathrm{Sr}(\mathrm{CH} 3 \mathrm{COO}) 2.2 \mathrm{H} 2 \mathrm{O}), \mathrm{ZnO}$, Acetone was used and all this chemicals are of Analytical grade. The appropriate concentration of Rhodamine $6 \mathrm{G}$ solution was prepared with distilled water.

\subsection{Instruments}

$\mathrm{Cd}$ and $\mathrm{Sr}$ doped $\mathrm{ZnO}$ crystallite was characterized using the field emission scanning electron microscope (FESEM) and Energy dispersive X-ray spectroscopy was from JEOL Ltd (JSM-7600F). The study of photocatalytic degradation of Rhodamine 6G was carried out in UV Photoreactor (25 W) from Nexa industry, Mumbai. The progress of Photocatalytic degradation (PCD) at an interval of $1 \mathrm{hr}$ in presence of UV light was checked by means of decrease in absorbance on colorimeter.

\subsection{Synthesis of cadmium and strontium doped zinc oxide}

Cadmium strontium doped zinc oxide was prepared by mechanochemical method. First step is preparation of metal oxalate complex and second step is decomposition of metal oxalate complex to obtain cadmium strontium doped zinc oxide. In this synthesis all chemicals were taken in non- stoichiometric amount. $819.5 \mathrm{mg}$ of oxalic acid dihydrate was mixed with $987.7 \mathrm{mg}$ of zinc acetate dihydrate, $26.5 \mathrm{mg}$ of cadmium acetate dihydrate and $82.0 \mathrm{mg}$ of strontium acetate in agate mortar and was hand ground for 30 mins at ordinary room temperature. During the process, the smell of acetic acid confirm the formation of metal oxalate complex. After 30 mins the product was washed with acetone. It was dried in an oven at $100^{\circ} \mathrm{C}$ for $3 \mathrm{hrs}$ and then calcined at $200^{\circ} \mathrm{C}$ for 30 mins. At last white powder of cadmium strontium doped zinc oxide was obtained[1].

$$
\begin{aligned}
& 3 \mathrm{C}_{2} \mathrm{H}_{2} \mathrm{O}_{4} \cdot 2 \mathrm{H}_{2} \mathrm{O}+\mathrm{Zn}\left(\mathrm{CH}_{3} \mathrm{COO}\right)_{2} \cdot 2 \mathrm{H}_{2} \mathrm{O}+\mathrm{Cd}\left(\mathrm{CH}_{3} \mathrm{COO}\right)_{2} \cdot 2 \mathrm{H}_{2} \mathrm{O}+\mathrm{Sr}\left(\mathrm{CH}_{3} \mathrm{COO}\right)_{2} \cdot 2 \mathrm{H}_{2} \mathrm{O} \\
& \text { Hand grind } \mathrm{Zn}\left(\mathrm{C}_{2} \mathrm{O}_{4}\right) \cdot 2 \mathrm{H}_{2} \mathrm{O}+\mathrm{Cd}\left(\mathrm{C}_{2} \mathrm{O}_{4}\right) \cdot 2 \mathrm{H}_{2} \mathrm{O}+\mathrm{Sr}\left(\mathrm{C}_{2} \mathrm{O}_{4}\right) \cdot 2 \mathrm{H}_{2} \mathrm{O}+6 \mathrm{CH}_{3} \mathrm{COOH}+6 \mathrm{H}_{2} \mathrm{O}
\end{aligned}
$$

$\mathrm{Zn}\left(\mathrm{C}_{2} \mathrm{O}_{4}\right) \cdot 2 \mathrm{H}_{2} \mathrm{O}+\mathrm{Cd}\left(\mathrm{C}_{2} \mathrm{O}_{4}\right) \cdot 2 \mathrm{H}_{2} \mathrm{O}+\mathrm{Sr}\left(\mathrm{C}_{2} \mathrm{O}_{4}\right) \cdot 2 \mathrm{H}_{2} \mathrm{O}$ calcination $\mathrm{Cd} \mathrm{Sr} \mathrm{ZnO}$ 
For the preparation of 5.218 X 10-6 M Rhodamine 6G solution, $0.025 \mathrm{~g}$ of Rhodamine $6 \mathrm{G}$ was taken and diluted it to $1000 \mathrm{ml}$ with distilled water. The photocatalytic activity of prepared photocatalyst was evaluate with the help of photocatalytic degradation of Rhodamine $6 \mathrm{G}$ dye under UV light irradiation, using $300 \mathrm{ml}$ of $5.218 \mathrm{X}$ 10-6 $\mathrm{M}$ of the dye solution and $0.3 \mathrm{~g}$ of photocatalyst. The solution was stirred and exposed to UV light for 7 hrs using UV photoreactor. An aliquot amount of $5 \mathrm{ml}$ solution were taken out from interval of $1 \mathrm{hr}$, filtered with the help of whatmann filter paper, the filtrate was used to check absorbance at $\lambda \max =500 \mathrm{~nm}$. The photodegradation of dye was checked by colorimeter.

\section{Results and discussion}

\subsection{Characterization of $\mathrm{Cd}$, $\mathrm{Sr}$ doped $\mathrm{ZnO}$}

For the characterization of materials, scanning electron microscope is widely used. It helps in the identification of surface morphology of prepared semiconducting materials. It has been seen that the $\mathrm{Cd}$ and $\mathrm{Sr}$ doped $\mathrm{ZnO}$ crystals are formed as micro scale than the nano scale by mechanochemical method. The addition of $\mathrm{Cd}$ and $\mathrm{Sr}$ by mechanochemical mean did not get the sufficient time and space to agglomerate the particles easily. The Figure no. 2 and Figure no. 3 of SEM reveals the formation of micro size semiconducting ZnO photocatalyst. The rod shape and its arrangement with 100nm scale is shown in Figure no.4.

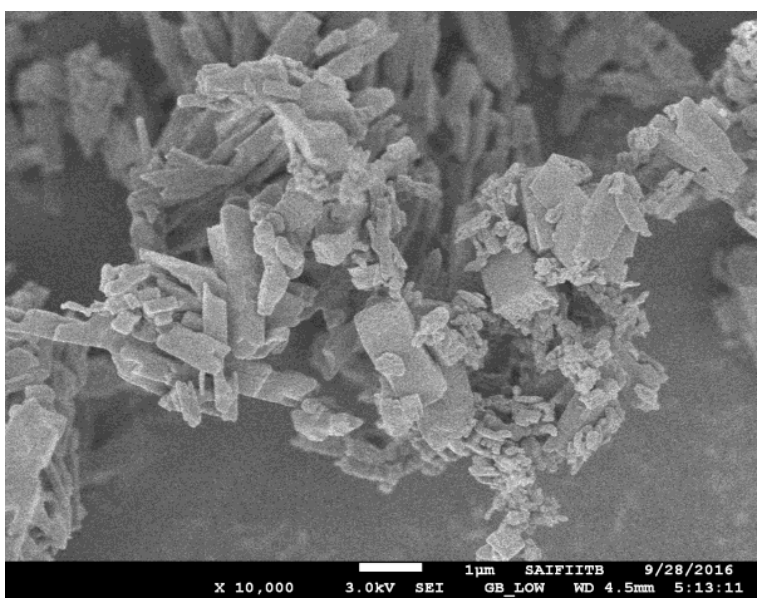

Fig. 2.

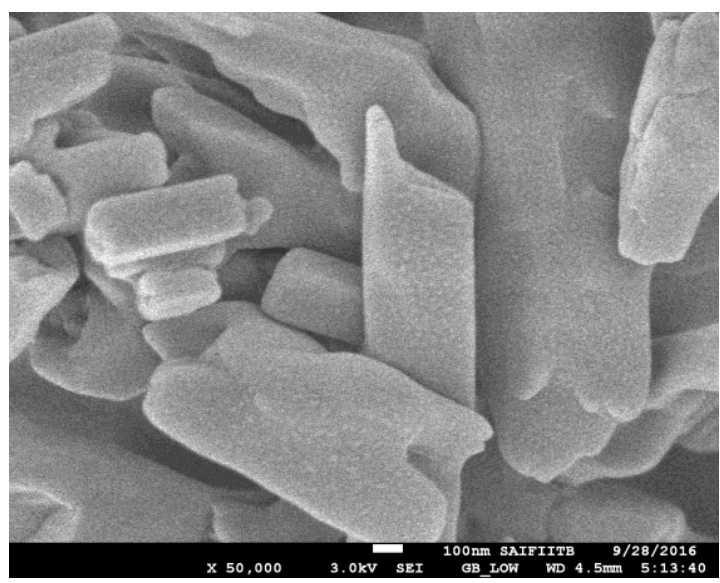

Fig. 4.

Fig. 2, 3 and 4. FE-SEM images of $\mathrm{Cd}$, $\mathrm{Sr}$ doped $\mathrm{ZnO}$ using different magnifications

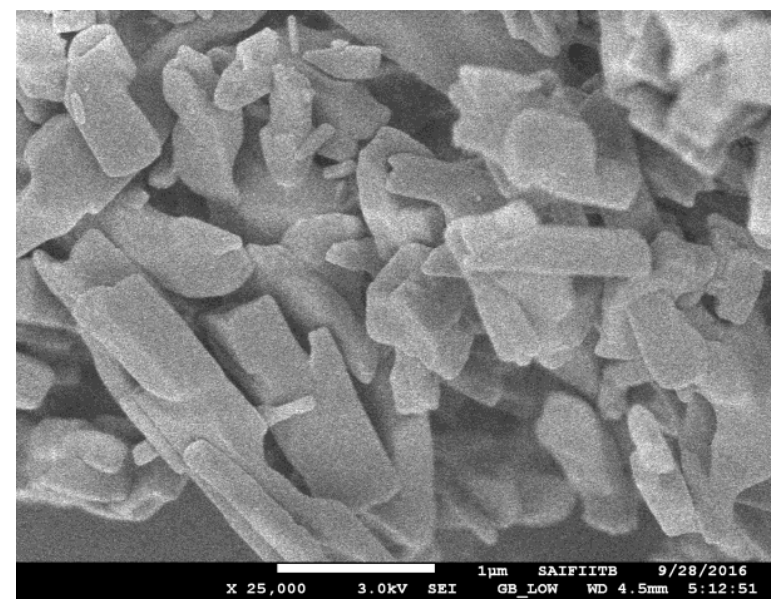

Fig. 3. 


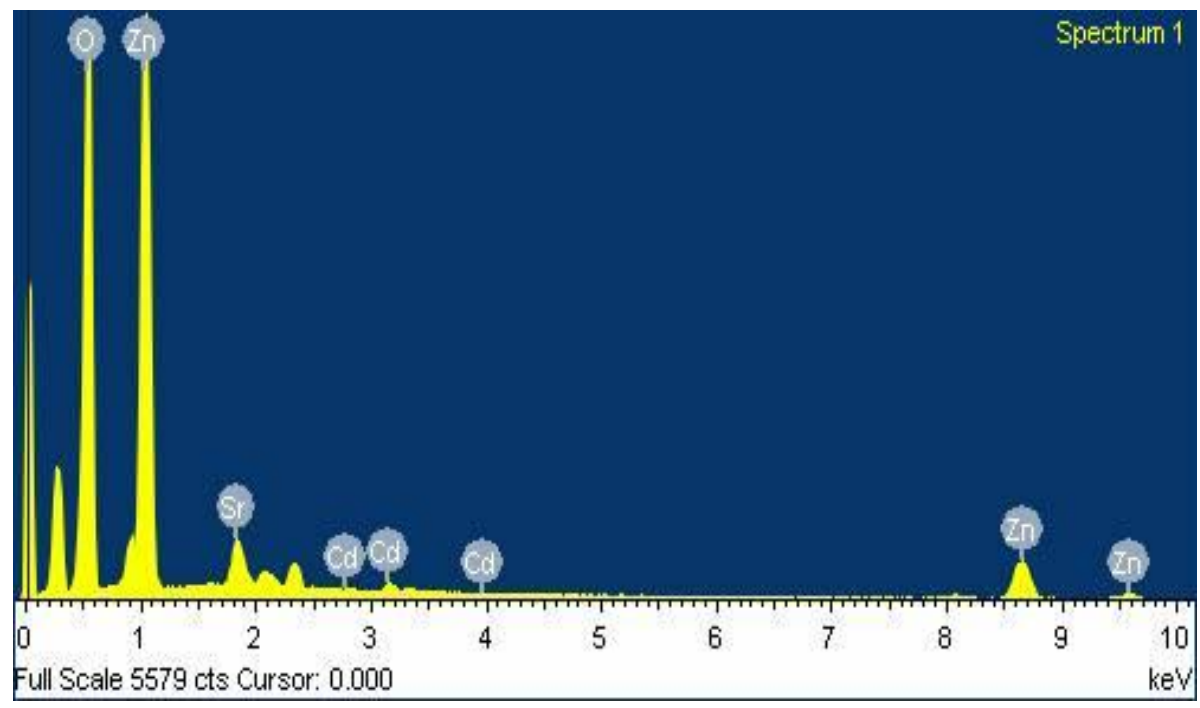

Fig. 5. EDX spectra of $\mathrm{Cd} \mathrm{Sr}$ doped $\mathrm{ZnO}$

Energy dispersive $\mathrm{x}$-ray spectrum of $\mathrm{Cd}, \mathrm{Sr}$ doped $\mathrm{ZnO}$ is shown in Figure 5. It shows peaks corresponds to $\mathrm{Zn}$, $\mathrm{O}, \mathrm{Cd}$, and Sr. Other impurities have not seen at any trace level in the direction limit of the EDX that strongly support, the doping of $\mathrm{Cd}$ and $\mathrm{Sr}$ in $\mathrm{ZnO}$ photocatalyst.

Table 1 Atomic Percentage

\begin{tabular}{|c|c|c|c|c|}
\hline & O & Zn & Cd & Sr \\
\hline Atomic Percent & $77.55 \%$ & $20.26 \%$ & $0.37 \%$ & $1.82 \%$ \\
\hline
\end{tabular}

The quantity of oxygen atoms in this sample is found more than theoretical value, that confirms sample was rich in oxygen, the site of $\mathrm{Zn}, \mathrm{Cd}$ and $\mathrm{Sr}$ may be replaced by oxygen as well as the amount of $\mathrm{Cd}$ and $\mathrm{Sr}$ found less than the actual amount doped in $\mathrm{ZnO}$ and this is because of inhomogeneity [6].

\section{a. Photocatalytic activity of $\mathrm{Cd}$ and $\mathrm{Sr}$ doped $\mathrm{ZnO}$}

Laser dye Rhodamine 6G was taken as a model organic pollutant for the study of $\mathrm{Cd}$ and $\mathrm{Sr}$ doped $\mathrm{ZnO}$ because it has toxic effect. The path for the photodegradation of organic pollutants is as follows [1]

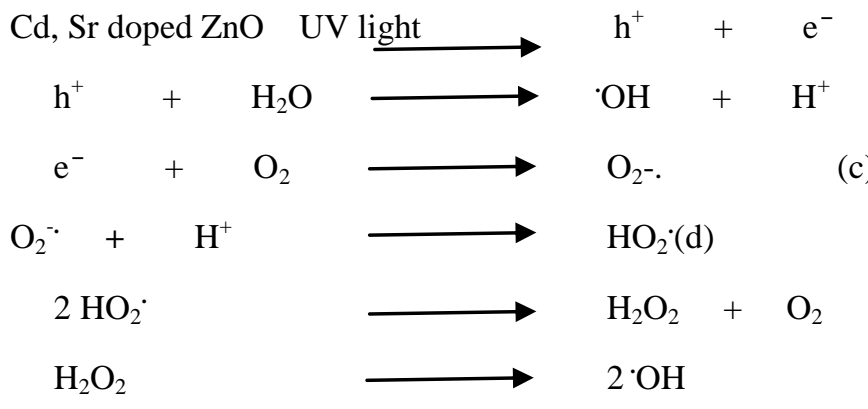

It has been seen that the Rhodamine $6 \mathrm{G}$ dye was taken about $8 \mathrm{hrs}$ to degrade completely with the help of $\mathrm{Cd}, \mathrm{Sr}$ doped $\mathrm{ZnO}$. The photocatalytic degradation study for pure $\mathrm{ZnO}$ and $\mathrm{Cd}$ and $\mathrm{Sr}$ doped $\mathrm{ZnO}$ for the dye Rhodamine $6 \mathrm{G}$ was carried out in UV photoreactor with $25 \mathrm{~W}$ light intensity. The $\%$ degradation of pure $\mathrm{ZnO}$ and $\mathrm{Cd} \mathrm{Sr}$ doped $\mathrm{ZnO}$ shows decrease in photocatalytic activity as shown in figure 6 . This is due to the slight increase in band gap of photocatalyst by doping in the mechanical path and the size of crystal in micrometer. That decrease the available surface area, which affect the rate of reaction. However the nature of photocatalytic efficiency of prepared $\mathrm{Cd} \mathrm{Sr}$ doped $\mathrm{ZnO}$ was found to the linear. 


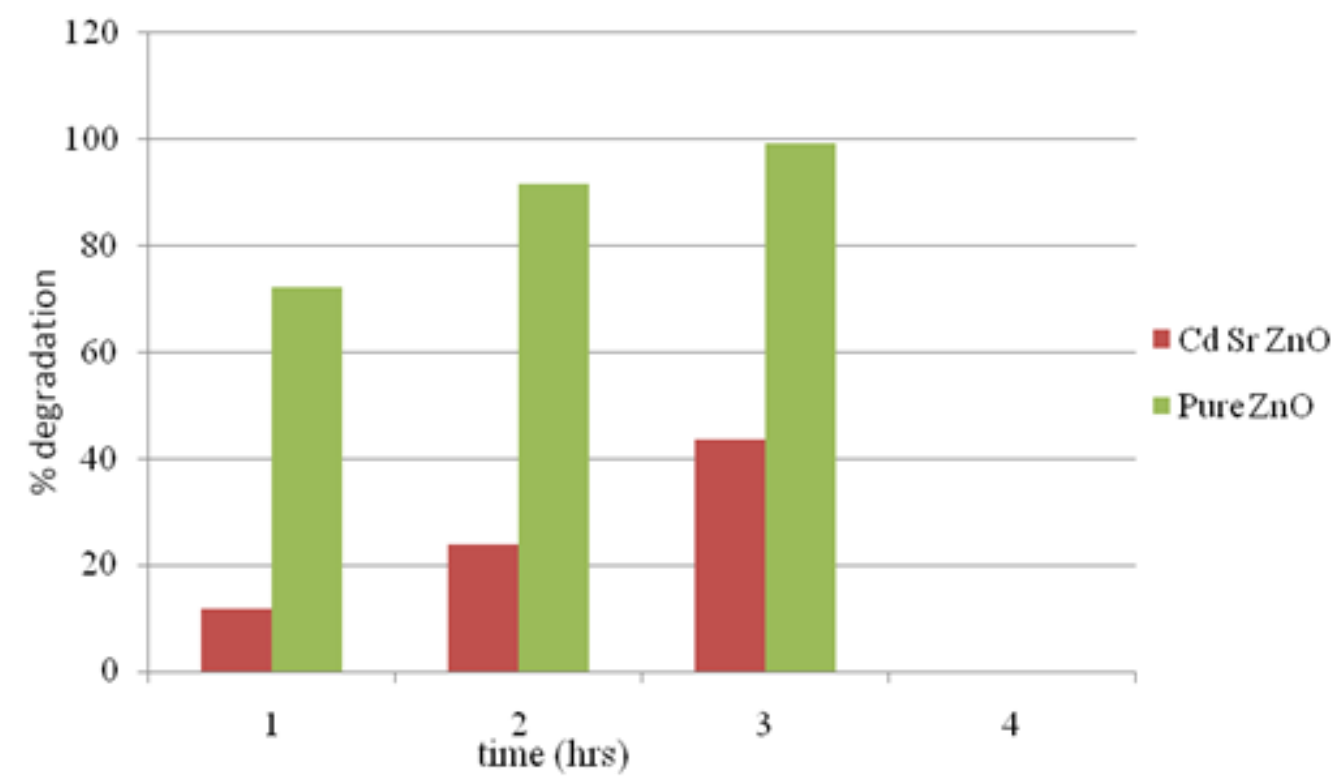

Fig. 6. Comparison of \% degradation vs. time

Figure 7 shows a plot of $\ln (\mathrm{Co} / \mathrm{Ct})$ in ppm versus irradiation time for photocatalytic degradation of Rhodamine 6G. The linearity of kinetic curve reveals that degradation of Rhodamine 6G follows apparent first order reaction kinetics.

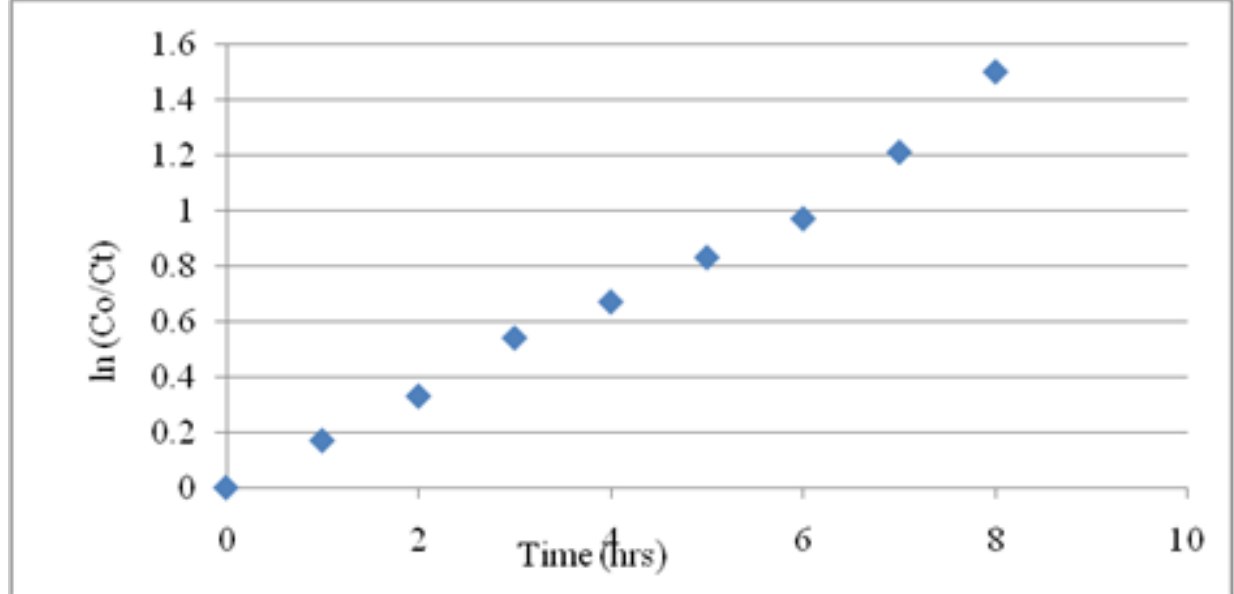

Fig. 7. Kinetic curve of Rhodamine $6 \mathrm{G}$ degradation

\section{Conclusions}

In the present work $\mathrm{ZnO}$ was doped successfully by ecofriendly Mechanochemical route. The SEM imgages shows that the particle size is in micro meter. EDX study confirmed the successfully doping of $\mathrm{Cd}$ and $\mathrm{Sr}$ in $\mathrm{ZnO}$. From Photodegradation of Rhodamine 6G in UV light, it was concluded that the Photocatalytic activity of $\mathrm{Cd}$, $\mathrm{Sr}$ doped $\mathrm{ZnO}$ is less than pure $\mathrm{ZnO}$.

\section{Acknowledgement}

The work is supported by Department of Chemistry, Dr. Babasaheb Ambedkar Technological University, Lonere, Raigad and IIT, Mumbai. 


\section{References}

[1] Ashokrao B. Patil, Kashinath R. Patil, Satish K. Pardeshi, "Ecofriendly synthesis and solar photocatalytic activity of S-doped ZnO”, Journal of Hazardous Materials, 183 (2010) 315-323.

[2] Ramin Yousefi, Farid Jamali-Sheini, Mohsen Cheraghizade, Sara Khosravi-Gandomani, Abdolhossein Saaedi, Nay Ming Huang, Wan Jefrey Basirun, Majid Azarang, "Enhanced visible-light photocatalytic activity of strontium -doped zinc oxide nanoparticles", Material Science in Semiconductor Processing, 32 (2015) 152-159.

[3] Safi Asim Bin Asif, Sher Bahadar Khan, Abdullah M Asiri, "Efficient solar photocatalyst based on cobalt oxide/iron oxide composite nanofibers for the detoxification of organic pollutants", Springer, 2014, 9:510.

[4] K. Rekha, M. Nirmala, Manjula G. Nair, A. Anukaliani, "Structural, optical, photocatalytic and antibacterial activity of zinc oxide and manganese doped zinc oxide nanoparticles", Physica B, 405 (2010) 3180-3185.

[5] Aracely Hernandez-Ramirez, Iliana Medina-Ramirez, Photocatalytic Semiconductors, Synthesis, Characterization, and Environmental Applications, Springer, New York, 2015. 